\title{
PARA UM ENSINO DE FILOSOFIA DO CAOS E DA FORÇA: UMA LEITURA À LUZ DA FILOSOFIA NIETZSCHIANA
}

\author{
Márcio DANElon ${ }^{*}$
}

\begin{abstract}
Algum dia necessitarão de instituiçõos em que se viva e se ensine como eu entendo viver e ensinar; talvez mesmo sejam instituídas cátedras próprias para a interpretação de Zaratustra.
\end{abstract}

(F. Nietzsche)

\begin{abstract}
RESUMO: Pretende-se, com este texto, elaborar uma reflexão em torno do ensino de filosofia recuperando como ferramenta teórica/ conceitual a filosofia de Nietzsche. Para isso, partiremos do conceito nietzschiano de filosofia deslocando-o para a temática do ensino de filosofia. Nesse cenário conceitual, iremos propor um ensino de filosofia cuja tarefa seja, num primeiro momento, a de instaurar o caos e o abismo na realidade humana como meios necessários para se forjar um homem forte. Num segundo momento, afirmaremos um ensino de filosofia que possa contribuir para a emergência daquilo que Nietzsche chamou de além-do-homem.
\end{abstract}

Palavras-chave: Filosofia. Força. Caos. Além-do-homem.

\section{FOR A TEACHING OF PHILOSOPHY OF CHAOS AND FORCE: ACCORDING TO THE NIETZSCHEAN PHILOSOPHY}

ABSTRACT: The aim of this paper is to elaborate a reflection on the teaching of Philosophy recovering the Nietzschean philosophy as a theoretical tool. For this, we will consider the Nietzschean philosophy moving it to the thematic of the teaching of philosophy. In this conceptual stage, we will propose a teaching of philosophy which has in the first moment to restore the chaos and the abyss of the human reality as a necessary means to forge a

Doutor em filosofia da educação pela Universidade Estadual de Campinas (UNICAMP) e professor de filosofia na Universidade Metodista de Piracicaba (UNIMEP) e nas Faculdades Claretianas de Rio Claro (UnICLAR). E-mail: madanelo@unimep.br 
Para um ensino de filosofia do caos e da força...

strong man. In the second moment, we will affirm a teaching of philosophy that may contribute to the emergency of what Nietzsche called beyond-the-man.

Key words: Philosophy. Force. Chaos. Beyond the man.

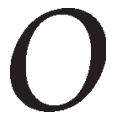

ensino de filosofia tem se constituído como uma área de pesquisa bastante fecunda e frutífera para os filósofos que se dedicam ao tema. A produção de conhecimentos vem se adensando e se cristalizando com bastante consistência neste início de século.

Dependendo da forma como se aborde a questão, o ensino de filosofia pode envolver áreas distintas do saber. Pode constituir-se em objeto de pesquisa tanto para aqueles que trabalham com o saber pedagógico como para aqueles que trabalham com a filosofia ou com a filosofia da educação. Neste aspecto, acreditamos ser importante pensar o ensino de filosofia desde um olhar da própria filosofia. Em outras palavras, pensar filosoficamente o ensino de filosofia (Cerletti, 2003) é pensar com a filosofia, com o saber filosófico, o problema de seu ensino. Embora envolva discussões de cunho específico da educação, por exemplo metodologias para o ensino de filosofia, didática teórica e prática, o ensino, em si, requer reflexão sobre esses temas a partir da filosofia e com a filosofia. Isso significa desconstruir a compartimentalização do saber com a qual, positivamente, estamos habituados. Assim, a didática, a metodologia e o objetivo do ensino de filosofia não devem se constituir em assunto específico da ciência da educação. Também os filósofos devem sair de seu "olhar distante" e se debruçar sobre tais questões, o que acarreta a produção de uma relação rizomática ${ }^{1}$ entre os saberes.

Talvez um elemento indispensável para se pensar filosoficamente o ensino de filosofia seja o próprio conceito de filosofia. Que filosofia queremos ensinar? Que conceito de filosofia o professor assume para si em sua prática pedagógica? Definir o conceito de filosofia é o passo fundante do processo de se ensinar filosofia; é dizer, desde o início, com qual autor, com qual referencial teórico irá trabalhar na sala de aula; é assumir, enfim, uma postura filosófica em torno dos problemas filosóficos emergidos no processo de ensino.

Na história da filosofia, encontramos inúmeras definiçōes de filosofia, cada qual pensada num contexto particular, para fins particulares, por exemplo a filosofia como contemplação da idéia perfeita, em Platão; a filo- 
sofia como caminho para o conhecimento do divino, na cristã; a definição por Merleau-Ponty de que a filosofia é re-apreender a ver o mundo; ou, ainda, a definição deleuzo-guatarriana da filosofia como a arte de criar ou fabricar conceitos, entre muitas outras possíveis definições. Ora, independentemente da definição de filosofia, cada qual irá refletir, de forma bastante importante, como se trabalhar o ensino de filosofia, ou seja, deverá conter em si o reflexo do autor e do conceito de filosofia que se tenha como cenário. Em última instância, significa deixar às claras os referenciais teóricos imanentes ao ensino de filosofia. Dessa forma, será o ensino de filosofia uma atividade sempre aberta, sempre em construção, com justificativas, conteúdos e objetivos singulares, reflexos da pluralidade de filosofias e da singularidade com a qual se olha para a filosofia. De fato, dada esta premissa, não há uma forma, uma metodologia específica, um conteúdo definido, uma justificativa ou objetivo unívoco no ensino de filosofia. Ao contrário, a filosofia é polissêmica e proporciona multipossibilidades de visadas; uma pluralidade de metodologias, justificativas e objetivos; uma infinidade de conteúdos filosóficos que tornam o seu ensino uma obra sempre aberta, dinâmica e em movimento.

Nesse contexto, gostaríamos de explorar o tema do ensino de filosofia tendo como cenário o pensamento do filósofo alemão Friedrich Nietzsche (1844-1900). Assim, demarcaremos, primeiro, o seu conceito de filosofia para, em seguida, refletirmos sobre o ensino de filosofia. Importante esclarecer que Nietzsche não desenvolveu em suas obras uma reflexão sobre o ensino de filosofia, porque este não the foi objeto de preocupação conceitual. Dessa forma, refletiremos a partir dos conceitos trazidos por Nietzsche. Trata-se, então, de pensar o ensino de filosofia com Nietzsche, tomando sua filosofia como caixa de ferramentas.

Em seu livro autobiográfico - Ecce homo - Nietzsche traz seu conceito de filosofia como a expressão de seu corpo filosófico. Para ele, a filosofia é a expressão da dureza, ${ }^{2}$ da força, do enfrentamento, do ar gélido dos cumes; a filosofia é para aqueles que possuem a força de espírito para a solidão, para o enfrentamento do medo, para aqueles que não se submetem à segurança dos ideais prontos:

Quem sabe respirar o ar forte de meus escritos sabe que é um ar da altitude, um ar forte. É preciso ser feito para ele, senão o perigo de se resfriar não é pequeno. O gelo está perto, a solidão é descomunal - mas com que tranqüilidade estão todas as coisas à luz! Com que liberdade se respira! Quan- 
Para um ensino de filosofia do caos e da força...

to se sente abaixo de si! - filosofia, tal como até agora entendi e vivi, é a vida voluntária em gelo e altas montanhas - a procura por tudo o que é estrangeiro e problemático na existência, por tudo aquilo que até agora foi exilado pela moral. De uma longa experiência que me foi dada por andanças pelo proibido, aprendi a considerar as causas pelas quais até agora se moralizou e idealizou, de modo muito diferente do que seria desejável: a história escondida dos filósofos, a psicologia de seus grandes nomes, veio à luz para mim. (Nietzsche, 1983, p. 366)

O exercício do pensar a filosofia é uma atividade fisiológica ${ }^{3}$ que requer a expressão da força como critério para sua elaboração. A metáfora da natureza é bastante explorada por Nietzsche na tentativa de expressar, de forma concreta, seu conceito de filosofia como expressão da dureza. No Zaratustra, Nietzsche afirma:

Tem coragem, irmão meu? Tem valentia? Não coragem diante de testemunhas, mas valentia de solitário e daquele ao qual nem mesmo um deus faz mais do que ser espectador. As almas frias, cegas, bêbadas, não são para mim corajosas. Tem coração aquele que conhece o medo, mas tem somente controle sobre o medo; aquele que olha para o abismo, mas com orgulho. Que olha para o abismo, mas com olhos de águia - que com garras de águia prende o abismo: isto constitui a coragem. (Nietzsche, 1997, p. 273)

A filosofia, para Nietzsche, é a expressão de um tipo de homem que tem em sua própria força, em sua coragem e em seu enfrentamento do medo, a causa motora. A filosofia é para aqueles que olham para o abismo sem medo da altura, porque trazem dentro de si o abismo, e para aqueles que têm o olhar de águia: forte, solitário, panorâmico.

Se a filosofia, para Nietzsche, é o ar puro e gelado das montanhas e dos cumes; se a filosofia é a dureza do espírito, então a filosofia é para aquele tipo de homem que tem no exercício da força e da superação de si sua característica peculiar. É preciso, segundo Nietzsche, ter ouvidos seletos ${ }^{4}$ para o desfrute da filosofia de ar puro e gelado.

Nietzsche conceitua a filosofia como a expressão do ar puro e gelado das montanhas, da dureza do espírito, da solidão e do enfrentamento. Assim, a dureza, a solidão, o exercício da força, a expressão da potencialidade da existência são características do homem fisiologicamente preparado para tal filosofia. O homem nietzschiano, para viver a filosofia, deve trazer dentro de si, em seu espírito, o ar puro e frio dos cumes das montanhas; deve trazer o abismo dentro de si e olhá-lo com o 
espírito da águia; deve trazer a força da tempestade, dos raios e trovões. Em última instância, o homem nietzschiano é o tipo de homem forte, com lastro fisiológico, com saúde necessária para esta filosofia, conforme a Genealogia da moral:

Os juízos de valor cavaleiresco-aristocrático têm como pressuposto uma constituição física poderosa, uma saúde florescente, rica, até mesmo transbordante, juntamente com aquilo que serve à sua conservação: guerra, aventura, caça, dança, torneios e tudo que envolve uma atividade robusta, livre, contente. (Nietzsche, 1988, p. 29-30).

A caracterização desse tipo de homem é expressa pelo seguinte esquema designativo: bom $=$ nobre $=$ poderoso $=$ belo $=$ feliz $=$ caro aos deuses. ${ }^{5}$ No aforismo, "Na escola bélica da vida", do Crepúsculo dos idolos, lemos: "O que não me mata me torna mais forte" (Nietzsche, 1995, p. 46). A mesma idéia encontramos no Ecce homo, um texto posterior (Nietzsche, 1995a, p. 25).

No caso, a premissa fundamental da tese nietzschiana é aquele tipo de homem saudável em sua constituição física e espiritual, capaz de fazer do combate, do desafio, da dificuldade a expressão de sua potencialidade e a realização de sua existência. $\mathrm{Na}$ constituição do homem, o estatuto da experiência ocupa papel central, à medida que o processo de potencialização da vida encontra na experiência da luta, da dureza, do enfrentamento seu meio de materialização. Em Para além do bem e do mal, encontramos a mesma caracterização do tipo humano, quando Nietzsche afirma:

Uma espécie nasce, um tipo se torna firme e forte na luta prolongada com condiçôes desfavoráveis essencialmente iguais. Das experiências de criadores se sabe que, inversamente, as espécies favorecidas com alimentação abundante, e sobretudo com proteção e cuidado extra, logo propendem fortemente à variação do tipo e são ricas em prodígio e monstruosidade (...) a espécie necessita de si mesma como espécie, como algo que justamente por sua dureza, uniformidade, simplicidade de forma pode se impor e se tornar duradouro, na constante luta com os vizinhos ou os oprimidos em revolta ou que ameaçam revoltar-se. (Nietzsche, 1992, p. 176-177)

Demarcado está, de fato, o conceito de filosofia desde o olhar nietzschiano e caracterizado o tipo humano que se enquadra nesse modelo de filosofia. Em ambos encontramos metáforas da natureza que os definem sempre do ponto 
Para um ensino de filosofia do caos e da força...

de vista da força, da dureza, do combate e da potencialização ascendente da vida. Portanto, o ensino de filosofia deve estar articulado aos conceitos de filosofia e de homem. No caso, afirmamos um ensino de filosofia cuja premissa teórica seria possibilitar a emergência de uma filosofia dos cumes gelados e, em contrapartida, a emergência de um homem forte e sadio o suficiente para vivê-la. Em outras palavras, o ensino de filosofia deve ter em seu horizonte a promoção de um tipo humano em que as crises, os solavancos, as vicissitudes e contingências inerentes à existência sirvam de alimento para a potencialização do próprio homem; que a solidão e o isolamento se constituam em possibilidades de refinamento do próprio ser; que, diante dos abismos da existência, o ensino de filosofia contribua para criar as possibilidades para a emergência do espírito da águia a fim de que o sujeito olhe o abismo de cima, arrogante, desafiador, exatamente porque traz o abismo dentro de si; um ensino de filosofia que faça de uma guerra perdida a força motriz para a superação da própria condição humana. Ora, é nos momentos de crise, de luta e derrotas, é nos momentos em que os abismos se apresentam no horizonte humano que a filosofia se faz mais necessária, conforme fragmento póstumo de Nietzsche:

A filosofia é uma forma através da qual se manifesta o atelier da natureza. Sobre o tumulto da história contemporânea a esfera do filósofo e do artista prospera ao abrigo da necessidade. O filósofo como travão da roda do tempo. E nas épocas de grande perigo que os filósofos aparecem - no momento em que a roda do tempo gira cada vez mais depressa - eles e a arte tomam o lugar do mito que desaparece. Mas eles lançam-se muito antecipadamente, pois a atenção dos contemporâneos só lentamente se volta para eles. Um povo que se torna consciente dos perigos produz o gênio. (Nietzsche, 1984, p. 23)

Assim, acreditamos num ensino de filosofia para o caos, para os momentos em que os valores se nulificam, os ideais perdem seu encanto e o niilismo toma conta da existência. Este é o palco da filosofia e de seu ensino. Este é o momento de sua necessidade. E é somente neste cenário que o homem pode mostrar seu poder de superação, sua capacidade de potencializar a vida e tirar de si mesmo a força para fazer das derrotas vitórias.

Com o referencial teórico cedido pela filosofia nietzschiana, postulamos um ensino de filosofia para o abismo e as contingências presentes na existência humana, ou melhor, um ensino de filosofia para os mo- 
mentos de crise porque o único valor inalienável é o valor da vida, da promoção e do engrandecimento da vida. Dessa forma, é nos abismos e nas contingências da vida humana que se encontra o cenário propício para a potencialização da vida. Para Nietzsche, talhar o homem na dureza do espírito significa ir aos abismos da existência, pois é do sucumbir que o homem forte, que o homem de caráter - como força - pode brotar. Assim, acreditamos num ensino de filosofia que instaure a solidão dos cumes gelados, que sucumba com o próprio sujeito, que o jogue no abismo para que, do fundo desse abismo, anuncie-se um homem talhado na dureza.

De outra forma, não compartilhamos, de fato, com a idéia de um ensino de filosofia para a formação da cidadania, por exemplo; de um ensino de filosofia para a formação de uma consciência crítica/reflexiva, ou para a promoção de valores humanistas ou, mesmo, de um ensino de filosofia para os valores de mercado do capitalismo. Os valores políticos - cidadania -, os valores ideológicos - consciência crítica -, os valores humanistas - justiça, paz - ou os valores capitalistas - formação e sucesso profissional - são valores contingentes, superficiais, demasiadamente tênues; são ídolos que formatam a existência humana. Em outras palavras, de que adianta uma consciência crítica diante de uma vida que se degenera, que entra numa espiral de decadência? De que adianta o exercício da cidadania diante de uma vida doentia, que se amedronta ante os abismos, que se consome, se dilui nas vicissitudes da vida? De que adianta o desfrute dos valores capitalistas diante de uma vida que não encontra nela própria a força necessária para superar a si mesma e suas contingências?

É importante sublinharmos que o processo de constituição de uma filosofia em que se evidencie a promoção de um tipo de homem e de um tipo de vida ascendentes encontra nos abismos e nas crises o elemento que impulsiona para o refinamento da existência. Nesse caso, temos, então, um ensino de filosofia instaurador da crise, um ensino de filosofia que faça do abismo sua essência pedagógica, porque é na crise e no abismo que se cinge um caráter forte e saudável. Pensamos, nesse cenário, num ensino de filosofia para o desafio, ou que tenha no desafio de colocar o sujeito na beira no abismo, de colocar o sujeito nos mais altos e gelados cumes, de colocar o sujeito no "olho do furacão" das vicissitudes da existência sua atividade pedagógica. Neste sentido, não acreditamos numa filosofia ou num ensino de filosofia para a resolução de problemas existenciais ao modo de uma clínica de aconselhamento, como também não acreditamos num ensino de filosofia para se discutir o sentido da vida ou construir, a partir da 
Para um ensino de filosofia do caos e da força...

filosofia, um sentido para a vida. Se as pessoas estão em queda no abismo, com sentimento de vazio existencial, não se deve fazer da sala de aula um grande divã para reencontrar o eixo da vida. Ao contrário disso, a filosofia e o ensino de filosofia não devem amortecer a crise, mas elevá-la, perpetuá-la, desafiar o sujeito a vivê-la; não deve construir um sentido para a vida, mas descentrá-lo, perdê-lo no caos. ${ }^{6}$ Ao modo da águia que não se amedronta diante do abismo porque ele faz parte de seu próprio espírito, o ensino de filosofia deve desafiar o sujeito a estar no abismo porque é nessa situação que se incorpora o abismo em seu espírito.

Para um ensino de filosofia pautado na valorização da vida e na ascensão do tipo humano forte cuja dureza do espírito seja o motor da superação de si, ou seja, de um homem talhado na mais dura madeira, ocupa papel central aquele que porta essa filosofia, aquele que traz, que anuncia esse novo homem. Em outras palavras, perguntamos quem é o educador/ professor que vai ensinar essa filosofia e esse tipo humano?

$\mathrm{Na}$ filosofia nietzschiana, encontramos na figura de Zaratustra o paradigma daquele que porta a filosofia sadia dos cumes gelados e que vem anunciar este homem cingido na dureza do espírito, ou seja, Zaratustra é o protótipo do professor de filosofia que deseja educar as pessoas na salutar solidão das montanhas. Ele é o modelo do educador para um ensino de filosofia para o desafio, porque Zaratustra viveu no cume da montanha, esteve com sua solidão, purificou seu espírito do ressentimento típico do último homem. Zaratustra é o paradigma do educador porque a sua filosofia é saudável, emergida da solidão, do ar gelado das montanhas, conforme lemos no preâmbulo de Assim falou Zaratustra: "Quando Zaratustra tinha trinta anos, ele deixou sua pátria e o lago de sua pátria e andou até a montanha. Durante dez anos, ele gozou de seu espírito e de sua solidão, sem se enfastiar" (Nietzsche, 1997, p. 5).

O processo pedagógico do Zaratustra educador começa quando ele, já portador de sua filosofia, resolve deixar a montanha para levar até os homens a sua sabedoria, para ensinar-lhes que o homem moderno, ou seja, o último homem deve ser superado. Zaratustra expressa a necessidade de descer da montanha para ter com os homens, para compartilhar com eles sua filosofia do futuro.

A figura de Zaratustra é a do educador porque faz da filosofia o estandarte que anuncia o tipo de homem superior, aquele que se acostuma com o gelo dos cumes. Zaratustra vem ensinar aos homens que os ideais, 
os valores e as ideologias que justificavam a civilização estão enterrados no niilismo do homem moderno.

O processo pedagógico de Zaratustra constitui-se em, primeiramente, instaurar o caos, o abismo e o niilismo na existência, ensinando aos homens que Deus está morto e que os valores que dignificavam o mundo humano perderam seu sentido e sua força. Zaratustra, então, faz o homem ver-se semelhante ao mais mesquinho e decadente dos seres: o último homem. Nesse caso, é necessária a queda no abismo do niilismo valorativo para se talhar um novo homem cuja dureza do espírito, solidão e superação de si sejam suas características.

Esse primeiro movimento pedagógico se constitui, na perspectiva nietzschiana, na própria tarefa da filosofia. Nesse caso, o projeto filosófico de Nietzsche, notadamente aquelas obras produzidas após o Zaratustra, é marcadamente uma crítica aos valores da modernidade, como valores de um tipo de homem fraco e ressentido. Em sua autobiografia, Nietzsche comenta essa tarefa da filosofia referindo-se ao seu livro Para além do bem e do mal:

A tarefa dos anos seguintes estava traçada da maneira mais rigorosa. Depois de ter resolvido a parte de minha tarefa que diz Sim (Zaratustra), era a vez da sua metade que diz Não, que faz o Não: tresvaloração mesma dos valores existentes, a grande guerra - a conjuração do dia da decisão. Nisso está incluído o lento olhar em volta, a busca de seres afins, daqueles que de sua força me estendessem a mão para a obra de destruição. (Nietzsche, 1995a, p. 95; parênteses meus)

$\mathrm{Na}$ perspectiva da tarefa da filosofia nietzschiana, efetivar a crítica aos valores que dão o fundamento ao homem e ao mundo modernos constitui-se no próprio compromisso do filósofo. É assim que as obras do terceiro período da produção filosófica de Nietzsche - a partir da segunda metade da década de 80 do século XIX -, entre as quais se destacam Para além do bem e do mal, Genealogia da moral, Crepúsculo dos ídolos, Ecce homo e $O$ anticristo, formam o corpo teórico da filosofia nietzschiana cujo objetivo é efetuar, talvez, as mais severas críticas à modernidade e a seus valores. Nesse cenário, emerge, para Nietzsche, uma filosofia a golpes de martelo, cuja tarefa é a de derrubar os ideais da sociedade moderna, derrubar os valores que nutrem um tipo de homem ressentido, fraco, doente. $\mathrm{O}$ papel da filosofia é dizer não a esses ideais, derrubá-los a golpes de martelo. A mesma idéia aparece no Ecce homo: "Eu não construo novos ídolos; os ve- 
Para um ensino de filosofia do caos e da força...

lhos que aprendam o que significa ter pés de barro. Derrubar idolos (minha palavra para 'ideais') - isto sim é meu ofício" (Nietzsche, 1995a, p. 18).

$\mathrm{O}$ procedimento pedagógico da filosofia nietzschiana constitui-se, então, na desconstrução dos valores modernos, momento sine qua non em que se torna impossível a emergência do além-do-homem. Nesse caso, o compromisso pedagógico da filosofia é com a derrubada dos ídolos e tornar possível ao homem reaprender a ver o mundo sem as lentes dos ideais modernos.

Nesse cenário conceitual, afirmamos um ensino de filosofia a golpes de martelo, ou seja, um ensino de filosofia cuja tarefa seja a desmistificação dos ideais modernos; um ensino de filosofia cuja tarefa seja a derrubada dos ídolos que nutrem e domesticam a humanidade, e que forjam homens que se dissolvem nos valores constituindo uma massa homogênea de pessoas iguais, pessoas do rebanho; um ensino de filosofia cuja tarefa seja a crítica dos valores políticos, sociais e religiosos, valores que se prestam ao processo de aniquilamento do homem livre e independente; um ensino de filosofia que observe esses ídolos como produto de interpretações e criações humanas, demasiadamente humanas. Afirmamos um ensino de filosofia que leve a fissura aos sólidos "pés de barro" dos valores do homem moderno; que leve a rachadura na tessitura conceitual das verdades da nossa civilização. Afirmamos, em última instância, um ensino de filosofia que leve o caos e o abismo para o homem moderno, ou seja, um ensino de filosofia que instaure o caos dentro de cada sujeito do processo educacional, como condição de possibilidade para, de dentro do caos, possa brotar uma estrela, conforme a citação de Zaratustra. Assim, afirmamos um ensino de filosofia que faça da praça seu espaço pedagógico, porque é na praça que encontramos o homem absorto nas questões do mercado, da sobrevivência material, da política, enfim, absorto nos ídolos da modernidade. Nesse caso, é preciso um ensino de filosofia que leve o abismo e o caos para a praça, que desvirtue o centramento valorativo do homem moderno, que corrompa com seus ídolos e suas verdades.

Esse primeiro movimento pedagógico da filosofia e de seu ensino é fundamental no programa filosófico porque é da crise que se brota a grande saúde, é do caos que uma estrela nasce, é do abismo e da solidão que se forja um homem forte para a guerra contra os ídolos modernos. Ora, a força do homem está, exatamente, em ele trazer dentro de si o caos, o abismo. Neste sentido, afirmar a vida, dizer sim à vida é geminado à negação, 
ao dizer não a ideais, valores e verdade que fundamentam a vida moderna, conforme aparece em Ecce homo:

Querem uma fórmula para um destino assim, que se fez homem? - Ela se encontra no meu Zaratustra. - e quem um criador quiser ser no bem e no mal, deverá ser primeiro um destruidor, e despedaçar valores. Assim o mal maior é próprio do maior bem: este, porém, é o criador. Eu sou, no mínimo, o homem mais terrível que até agora existiu; o que não impede que eu venha a ser o mais benéfico. Eu conheço o prazer de destruir em um grau conforme à minha força para destruir - em ambos obedeço à minha natureza dionisíaca, que não sabe separa o dizer Sim do fazer Não. Eu sou o primeiro imoralista: e com isso sou o destruir par excellence. (Nietzsche, 1995a, p. 110)

Assim, a emergência de uma filosofia saudável, dos cumes gelados, uma filosofia afirmadora da vida, torna-se possível no chão de uma consciência fértil e capaz de germinar. É preciso destruir os pastos do homem do rebanho para que novos frutos germinem, frutos saudáveis.

Nesse contexto emerge o segundo movimento pedagógico da filosofia de Nietzsche: a sua filosofia que diz Sim à vida, à terra e ao próprio homem como possibilidade de superação de si. Nesse caso, a filosofia desempenha a tarefa pedagógica de transcender a condição atual do homem moderno, marcadamente ressentido e fraco, para o modelo de homem forte porque traz em si o ar gelado dos cumes, o abismo e o caos. Assim, a educação do Zaratustra constitui-se em ensinar que o além-do-homem está por vir, está num futuro. Zaratustra é o anunciador do futuro do homem:

Meu irmão, eu vos ensino e vos indico a via de uma nova nobreza: para mim deve ser o pai e o criador e o semeador do vir-a-ser - contudo, não uma nobreza que se possa comprar como a mercadoria e com ouro: pouco valor tem, ao contrário disso, tudo aquilo que tem um preço. Não a vossa proveniência, ao contrário, e o vosso fim constituem, de agora em diante, a vossa honra! A vossa vontade e os vossos pés, que querem andar para além de lá e para além de vos mesmo - isto constitui a vossa nova honra. (Nietzsche, 1997, p. 190-191)

Zaratustra, como o paradigma do professor de filosofia, emerge como aquele que vem ensinar e anunciar a necessidade de superação do homem moderno, do último homem, e a emergência do além-do-homem, do homem das alturas, do homem sadio, conforme as palavras de Nietzsche: "O homem é uma corda, atada entre o animal e o além-do-homem - uma cor- 
Para um ensino de filosofia do caos e da força...

da sobre um abismo. Perigosa travessia, perigoso a-caminho, perigoso olhar-para-trás, perigoso arrepiar-se e parar" (Nietzsche, 1983, p. 227).

A tarefa pedagógica de Zaratustra educador revela-se quando ele desce da montanha, deixa sua solidão e vem ter com os homens, ensinando o além-do-homem, conforme o preâmbulo dessa obra:

Chegando à cidade mais próxima, às margens do bosque, Zaratustra encontrou próxima do mercado uma grande multidão: estavam anunciando o espetáculo de um equilibrista. E Zaratustra falou dessa forma para as pessoas: Eu vos ensino o além-do-homem. O homem é qualquer coisa que deve ser superado. Que coisa vós fizestes para superá-lo? (...) Eis que eu vim ensinar o além-do-homem. O além-do-homem é o sentido da terra. A vossa vontade diz: o além-do-homem seja o sentido da terra. (Nietzsche, 1997, p. 7-8)

Numa outra passagem, fica bastante clara a tarefa pedagógica de Zaratustra em anunciar o além-do-homem:

Foi ali, também, que eu recolhi do caminho a palavra "além-do-homem", e que o homem é algo que tem de ser superado:

- que o homem é uma ponte e não um fim: proclamando-se venturoso, seja de seu meio-dia ou de seu anoitecer, como caminho para novas auroras:

- a palavra de Zaratustra sobre o grande meio-dia, e tudo o mais que eu suspendi sobre os homens, igual a segundos ocasos de púrpura. Em verdade, também novas estrelas eu os fiz ver, assim como novas noites; e sobre nuvens e dia e noite estendi ainda o riso como um dossel colorido. Ensinei-lhes todo meu engenho e arte: adensar e juntar em um o que é fragmento no homem, e enigma e horrível acaso -

- com poetas, decifradores de enigmas e redentores do acaso ensinei-os a criar o futuro e tudo o que foi, a redimir criando. (Nietzsche, 1983, p. 250)

Nesse caso, a atividade pedagógica de Zaratustra revela-se em sua tarefa de se dirigir aos homens para anunciar o porvir: a superação do último homem e a emergência do além-do-homem. Nessa tarefa, Zaratustra revela-se um sábio cuja ação consiste em preparar as pessoas para a emergência do além-do-homem por intermédio do ensino de uma filosofia dos cumes gelados e da solidão, e da instauração do caos e do abismo no espírito do sujeito.

Em última instância, afirmamos um ensino de filosofia cujo objetivo consista na criação das possibilidades para a emergência do além-do-homem; um ensino de filosofia que contribua em forjar um homem de espírito duro 
o suficiente para experimentar o ar gelado, o abismo, o caos e a solidão; um ensino de filosofia da força para que o sujeito faça da crise e da guerra a essência de seu ser; um ensino de filosofia que possa criar as condições para talhar um homem saudável, afirmador de si mesmo e que promova o enobrecimento e a potencialização da vida; um ensino de filosofia que contribua na promoção da emergência de um tipo de homem que faça em sua existência uma guerra de morte contra os valores, os ídolos e os ideais potencializadores de um modo de vida marcada pelo ressentimento e de um tipo de homem fraco; um ensino de filosofia que contribua na promoção da emergência de um tipo de homem criador, ou seja, um homem que crie para si mesmo seus valores, um homem dançarino ao modo do Zaratustra; um ensino de filosofia, enfim, que não faça do telos da existência a velhice, mas, à luz do eterno retorno, que faça do fim último da existência a perpetuação da criança, desde o ser, livre, alegre, que brinca com a vida, que faz da experiência o seu cotidiano e que não tem memória, esta madrasta que nos faz lembrar dos valores e ídolos que empobrecem a vida.

\section{Recebido em maio de 2004 e aprovado em junho de 2004.}

\section{Notas}

1. Sobre a descompartimentalização do saber a partir do deslocamento do conceito deleuziano de rizoma, ver o livro de Sílvio Gallo, Deleuze e a educação, 2003.

2. Conforme as palavras de Nietzsche, em que lemos: "É necessário nunca haver se poupado, é necessário ter a dureza entre os seus hábitos, para estar bem e sereno entre somente duras verdades" (Nietzsche, 1997, p. 56).

3. Cf. Nietzsche, em Ecce homo, Por que sou tão inteligente, aforismos 01 e 02.

4. Cf. Nietzsche, em Ecce homo, Por que escrevo tão bons livros, aforismos 01-04.

5. Cf. Nietzsche, em Genealogia da moral, Primeira dissertação, aforismo 07.

6. Cf. as palavras de Nietzsche no Assim falou Zaratustra: "Eu vos digo: é necessário ter em si, ainda, o caos, para parir uma estrela dançante. Eu vos digo: vos tens ainda o caos dentro de si” (Nietzsche, 1997, p. 12).

\section{Referências bibliográficas}

CERLETTI A. Ensino de filosofia e filosofia do ensino filosófico. In: Gallo, S.; Cornelli, G.; Danelon, M. (Org.). Filosofia do ensino de filosofia. Petrópolis: Vozes, 2003. p. 61 e ss. 
Para um ensino de filosofia do caos e da força...

GALLO, S. Deleuze e a educação. Belo Horizonte: Autêntica, 2003.

NIETZSCHE, F. A gaia ciência. São Paulo: Hemus, 1981.

NIETZSCHE, F. Obras incompletas. 3. ed. São Paulo: Abril Cultural, 1983. (Coleção Os Pensadores)

NIETZSCHE, F. O livro do filósofo. Porto: Rés, 1984.

NIETZSCHE, F. Genealogia da moral. São Paulo: Brasiliense, 1988.

NIETZSCHE, F. Despojos de uma tragédia. Lisboa: Relógio d'Água, 1991.

NIETZSCHE, F. Para além do bem e do mal. São Paulo: Companhia das Letras, 1992.

NIETZSCHE, F. Crepuscolo degli idoli. Milão: Arnoldo Mondadori Editore, 1995.

NIETZSCHE, F. Ecce homo, São Paulo: Companhia das Letras, 1995a.

NIETZSCHE, F. Così parlò Zarathustra. Milão: Arnoldo Mondadori Editore, 1997. 